\title{
Assessment of complementary feeding practice in children 6-23 months
}

\section{of age in Mosul city}

\author{
Luay Amjed AL-Waly*
}

Dr. Nashwan M. AL-Hafidh**

\begin{abstract}
Background and Objectives: Proper feeding practices of children less than 2 years of age is important because it is the most critical period of life for optimal growth and development. This study aims to use the newly developed World Health Organization (WHO) infant feeding Indicators published in 2008, to assess complementary feeding practice in children 6-23 months of age in Mosul city.

Materials and Methods: A cross-sectional study was conducted in six primary health care (PHC) centers in Mosul city during 3 months period from $11^{\text {th }}$ of February to $11^{\text {th }}$ of May 2013. The study sample consists of (422) healthy convenient children who attended (PHC) centers for immunization. The questionnaire data filled by the researcher in a direct interview with consent mothers, utilizing the key indicators recommended by the WHO (2008) used to assess infant and young child feeding (IYCF) practices which include minimum dietary diversity, minimum meal frequency and minimum acceptable diet calculated for the age ranges $6-23$ months of age, and based on the mother's recall of foods given to her child in the 24 hours before the interview. The questionnaire subsumed inquires about source of feeding advice practiced by the studied mother. Statistical processing was conducted by the use of version 17 SPSS statistical package.

Results: A total of 422 children were enrolled in this study; 231(54.7\%) boys and $191(45.3 \%)$ girls. The mean age of the studied children is $12.4 \pm 4.97$ months. Less than half $192(45.5 \%)$ of the children 6-23 months of age met the minimum dietary diversity criteria whereas 334(79.1\%) met the minimum meal frequency criteria and only $172(40.8 \%)$ of the sample achieve the minimum acceptable diet criteria. Grain is the most frequent type of food consumed by 6-23 months aged children followed by dairy products, fruits and vegetables, egg, vitamin A-rich fruits and vegetables, and finally meat and legumes in decreasing frequency.

Conclusion: the family was the principal source of advice on child feeding practice.

Key words: Complementary feeding, Mosul, new WHO indicators, infant and young child feeding, dietary diversity, meal frequency and minimum acceptable diet.
\end{abstract}

\section{INTRODUCTION}

The time between the birth of a child and two years of life is the most critical period of life for optimal growth and development (Imdad et. al., 2011). Early growth faltering is difficult to reverse after the first 2 years of life (Krebs et. al., 2011). Poor breastfeeding and complementary feeding practices coupled with high rates of infectious diseases are the principal causes of malnutrition during the first two years of life(PAHO and WHO, 2003) . It is well recognized that the period of complementary feeding from 6 to 24 months of age is one of the most critical times for preventing malnutrition (World Bank, 2006).It is only after the sixth month of life that the nutritional requirements of infants cannot be provided only via breast milk (WHO, 1998). From this age on most infants reach a general and neurological stage of development (chewing, swallowing, digestion and excretion) that enables them to be fed other foods rather than breast milk and complementary feeding needs to be introduced to them (WHO, 1998). The nutritional adequacies of complementary foods are essential for prevention of infant morbidity and mortality, including under nutrition and overweight (WHO, 2000). Appropriate complementary feeding depends on accurate information and skilled support from the family, community and healthcare system.

Inadequate knowledge about appropriate food and feeding practices is often a greater determinant of malnutrition than the lack of food. Knowledge of mothers about these factors will be of help in planning interventions to improve feeding practices. Improving infant and young child nutrition must be a priority for all health personnel, not limited to the domain of nutritionists and they must have the knowledge and technical skills needed to appropriately counsel mothers on breastfeeding and complementary feeding and treat

* Assist Lecturer / College of Nursing/University of Mosul/Email: Luaay_amjed84@yahoo.com

** F. I.B.M.S (Pediatrics) 
illnesses that lead to poor nutrition, Nurses and physicians could be motivated through highlighting evidence of the importance of young child feeding and nutrition for child health(Caulfield et. al., 2004). The present study aimed to assess the frequency and diversity of complementary feeding in children 6-23 months of age . it also aimed to determine the frequency of minimum acceptable diet consumption in studied samples.

\section{MATERIAL AND METHOD}

A cross-sectional study design was chosen to fulfill the objectives of this research which is conducted in six primary health care (PHC) centers during the period from $11^{\text {th }}$ of February to $11^{\text {th }}$ of May 2013. The local ethical committee approved this study. The study sample consists of (422) convenient healthy children samples who attended (PHC) for routine immunization. The questionnaire data was filled by the researcher in a face-to-face interview. Complementary feeding practices among enrolled sample were assessed utilizing the key indicators recommended by the WHO (2008) to assess infant and young child feeding (IYCF) practices which were based on mother's recall of foods given to the child in the 24 hours before the interview (WHO,2008). The following outcome measures were estimated:-

1- Minimum dietary diversity: Proportion of children 6-23 months of age who receive foods from four or more food groups of the seven food groups.The seven foods groups used for tabulation of this indicator were: grains, roots and tubers; legumes and nuts; dairy products (milk, yogurt, cheese); flesh foods (meat, fish, poultry and liver/organ meats); eggs; vitamin A-rich fruits and vegetables; and fruits and vegetables other than those rich in vitamin A. Consumption of any amount of food from each food group is sufficient to 'count', i.e. there is no minimum quantity, except if an item is only used as a condiment.

2-Minimum meal frequency: Proportion of breastfed and non-breastfed children 6-23 months of age who receive solid, semi-solid or soft foods (but also including milk feeds for nonbreastfed children) the minimum number of times or more. Minimum was defined as: two times for breastfed infants 6-8months, three times for breastfed children 9-23 months and four times for non-breastfed children 6-23 months.

3-Minimum acceptable diet: Proportion of children 6-23 months of age who receive a minimum acceptable diet (apart from breast milk). This composite indicator is calculated from the following two fractions: breastfed children 6-23 months of age who had at least the minimum dietary diversity and the minimum meal frequency during the previous day, and non-breastfed children 6-23 months of age who received at least two milk feedings and had at least the minimum dietary diversity not including milk feeds and the minimum meal frequency during the previous day.

Descriptive statistical methods (Frequency and percentage) were used to analyze the data in this study. Statistical processing was conducted by the use of version 17 SPSS statistical package.

\section{RESULTS}

Table (1): Demographic characteristics of studied children 6-23 months of age $(n=422)$

\begin{tabular}{|l|c|c|}
\hline Variables & Frequency & $\%$ \\
\hline Age (months) \\
\hline 6-11months & 204 & 48.3 \\
\hline $12-17$ months & 122 & 28.9 \\
\hline 18-23 months & 96 & 22.7 \\
\hline Mean age 12.4 \pm 4.97 months \\
\hline \multicolumn{3}{|l|}{ Sex } \\
\hline Male & 231 & 54.7 \\
\hline Female & 191 & 45.3 \\
\hline
\end{tabular}

Table (2): Frequency of different complementary food groups intake by studied children 6-23 months of age $(n=422)$.

\begin{tabular}{|c|c|c|c|}
\hline Food group & Intake & Frequency & $\mathbf{\%}$ \\
\hline \multirow{2}{*}{ Grain } & Yes & 374 & 88.6 \\
\cline { 2 - 4 } & No & 48 & 11.4 \\
\hline \multirow{2}{*}{ Legumes } & Yes & 90 & 21.3 \\
\cline { 2 - 4 } $\begin{array}{c}\text { Dairy } \\
\text { products }\end{array}$ & Yo & 332 & 78.7 \\
\cline { 2 - 4 } Meat & No & 233 & 55.2 \\
\hline \multirow{2}{*}{ Eggs } & Yes & 189 & 44.8 \\
\cline { 2 - 4 } & Yo & 304 & 28.0 \\
\cline { 2 - 4 } & No & 259 & 72.0 \\
\hline $\begin{array}{c}\text { Vitamin A } \\
\text { rich fruit and } \\
\text { vegetables }\end{array}$ & Yes & 137 & 32.6 \\
\cline { 2 - 4 } $\begin{array}{c}\text { other } \\
\text { vegetables and } \\
\text { fruits }\end{array}$ & Yo & 285 & 67.5 \\
\cline { 2 - 4 } & No & 212 & 50.2 \\
\hline \multirow{2}{*}{ Mes } & 210 & 49.8 \\
\hline
\end{tabular}

Table (3): Complementary feeding indicators among children 6-23 months of age $(n=422)$.

\begin{tabular}{|c|c|c|}
\hline Variable & $\begin{array}{c}\text { Achieved } \\
\text { No. (\%) }\end{array}$ & $\begin{array}{c}\text { Not Achieved } \\
\text { No. (\%) }\end{array}$ \\
\hline Minimum dietary diversity & $192(45.5)$ & $230(54.5)$ \\
\hline Minimum meal frequency & $334(79.1)$ & $88(20.9)$ \\
\hline Minimum acceptable diet & $172(40.8)$ & $250(59.2)$ \\
\hline
\end{tabular}


Table (4): Source of complementary feeding nutritional advice offered to mothers of children 6-23 months of age $(n=422)$

\begin{tabular}{|l|c|c|}
\hline Variables & Frequency & $\mathbf{\%}$ \\
\hline Doctor & 17 & 4.0 \\
\hline PHC & 3 & 0.7 \\
\hline TV & 5 & 1.2 \\
\hline Family & 301 & 71.3 \\
\hline More than one & 96 & 22.7 \\
\hline Total & 422 & 100.0 \\
\hline
\end{tabular}

\section{DISCUSSION}

Infant and young child feeding (IYCF) practices, comprising of both breast feeding and complementary feeding, rank among the most effective means to improve nutritional status and the survival of a child (Black et. al., 2008). This is the first study describing complementary feeding indicators in Iraq using the recommended new infant feeding indicators. Discussion of the study findings are organized into the following:

\section{Foods groups:-}

The WHO guidelines (2008) recommend that complementary foods for infants after six months of age be made from seven food groups namely grains, roots and tuber; legumes and nuts; dairy products (milk, yogurt, cheese); flesh foods (meat, fish, poultry and liver/organ meats); eggs; vitaminA rich fruits and vegetables and other fruits and vegetables (WHO, 2008and 2010). Majority $(88.6 \%)$ of enrolled children aged 6-23 months consumed foods made from grains in the 24-hour period prior to the interview (Table2), which is concordant with the finding in Basra's study in which $(85.1 \%)$ of children were given rice and cereals (Saleem, 2006). Findings of this research were also in conformity with studies conducted in Bangladesh, India, Nepal where in Bangladesh About (85\%) of children aged 6-23 months were given grains (Kabir et. al., 2012), in India (82.6\%) (Patel et. al., 2012) and in Nepal (90\%) of similar children consumed grains(Joshi et. al., 2012). Grain is the predominant type of food consumed by 6-24 months aged children from an international sample of healthy breastfed infants from widely differing ethnic backgrounds and cultural settings (Brazil, Ghana, India, Norway, Oman and USA) (WHO,2006).38.6\% of studied children had eggs intake and $28.0 \%$ of them were meat consumers (Table2). Meat and fish were administered less frequently (15\%) to children aged 6-24 months lived in Basra (Saleem , 2006 ). In Egyptian health survey which was carried out in $2008,59.7 \%$ of breastfeeding children age 6-23 months consumed foods made from meat and eggs in the 24-hour period prior to the survey (ElZanaty and Ann,2009). About one third (31\%) of Jordanian children age 6-23 months received meat, fish, poultry or eggs (Nsour et. al., 2008). Flesh food was consumed by $59.5 \%$ and $69.4 \%$ of 12 months and 18 months old American children respectively (WHO,2006b). A relatively lower percentages $(17 \%)$ of children in Nepal had received flesh foods and (6\%) got eggs offered during the past 24 hours(Joshi et al,2012). Hotz and Gibson(2001), Macharia-Mutie et. al. (2010) and Hope et. al. (2000) observed that children were less likely to consume animal protein foods in their daily diet in Malawi, Kenya and Vietnam . Only $4 \%$ and $5.7 \%$ of children aged 6-23 months consumed eggs, meat and fish in rural Malawi and Vietnam. Dang et al. (2005) found that less than $30 \%$ of Tibetan children under 2 years consumed eggs, meat and fresh vegetables on daily basis because these foods are expensive and only few can afford to purchase. The frequency of consumption of meats was relatively low in a Lebanese study (Batal et. al., 2010). Economic constraints were the main reason for the low frequency of animal protein consumption stated by some researchers (Macharia-Mutie et. al., 2010; Dang et. al., 2005). Low consumption rates of egg and meat in India (5.3\%), (7.7\%) respectively were attributed to the traditional beliefs that infants fail to digest animal foods(Patel et. al., 2012; Batal et. al., 2010). Differences in the rate of food group intake in different populations might be due to negative beliefs (Paul et. al., 2011) and inadequate knowledge about the importance of feeding young children variety of foods among mothers and caregivers (Joshi et. al., 2012). Lack of affordability of these foods has been reported to be the main limiting factor for their daily consumption(Joshi et. al., 2012; Dang et al, 2005 ). In the present study, vitamin A-rich fruits and vegetables were eaten by only $32.5 \%$ of children while $50.2 \%$ of the sample ate other fruits and vegetables, whereas $84 \%$ of last-born Jordanian children aged 6-35 months living with the mother consumed vitamin A-rich foods in the 24-hour period before the survey (Nsour et. al., 2008).This low vitamin A-rich fruits and vegetables intake among children in Mosul city emphasizes the need for vitamin A supplementation and health professional's guidance to enhance vitamin A intake rate through good selection of complementary foods . Kabir et al(2012) reported that about $54 \%$ of children in Bangladesh had vitamin A-rich fruits and vegetables and $47 \%$ had other fruits and vegetables. In Nepal, about (48\%) of children had received vitamin A-rich foods whereas only $(25 \%)$ received fruits and vegetables 
Joshi et al(2012) and Patel et al (2012) found that less than $(34.4 \%)$ of studied Indian children ate vitamin A-rich fruits and about (15.4\%) ate other fruits and vegetables.Differences in the dietary schedules during the complementary feeding in most countries originate from cultural reasons( Kuriyan and Kurpad , 2012). Only $21.3 \%$ of selected children received legumes(Table2); close to a (30.8\%) result found in Egyptian survey (El-Zanaty and Ann , 2009).Legumes were consumed by $33.9 \%$ and $43.4 \%$ of 12 months and 14 months old American children. respectively (WHO,2006) whereas (15.2\%) of Basra's children ate legumes (Saleem , 2006 ). Dairy products were consumed by $55.2 \%$ of enrolled children compared to $62.5 \%$ Egyptian breast fed children(El-Zanaty and Ann , 2009), and $73.7 \%$ Jordanian breast fed children aged 6-23 months (Nsour et. al., 2008).

\section{Complementary feeding indicators :- \\ Minimum dietary diversity:-}

In present study, less than half $(45.5 \%)$ of children 6-23 months of age meet the minimum dietary diversity criteria (Table 3 ). This indicates that more than half of studied children 623 months of age fail to receive foods from four out of seven classified food groups. Similar to our findings, in Bangladesh, the rate of minimum dietary diversity was $(41.9 \%)$ and in Nepal it was (34.2\%) (Kabir et al, 2012; Joshi et. al., 2012) . In Egypt $55 \%$ of children age 6-23 months had an adequately diverse diet (El-Zanaty and Ann,2009) . $75.1 \%$ of matched Jordanian's children had an adequately diverse diet (El-Zanaty and Ann, 2009). In Sri Lanka (Senarath et. al., 2012) and Indonesia(Charmaine et. al., 2012) , the prevalence of minimum dietary diversity were high $71.1 \%$ and $68.4 \%$ respectively, while in India the minimum dietary diversity rate is low (15.2\%) (Patel et. al., 2012). Appropriate support and counseling of mothers regarding optimum complementary feeding choice and practice are required to improve dietary diversity in our locality. Education of parents is important as it makes better decision to promote their children's growth and health (Nasmah and Mohammed ,2001).

\section{Minimum meal frequency:-}

The minimum meal frequency criterion was achieved by $(79.1 \%)$ of the enrolled sample (Table 3). In Egypt, Jordan and Morocco, rates of meal frequency are (58\%), (62\%) and (62\%) respectively (WHO,2010a); indicating that studied children in Mosul city ate more frequently but with less diversity than the compared samples. In Bangladesh Kabir et al(2012) and in Sri Lanka Senarath et al(2012), the rates of minimum meal frequency were $(81.1 \%),(88 \%)$ respectively, which is similar to our findings, whereas in the SubSaharan African countries, rates of meal frequency among children aged 6-23 months are lower than 50 percent as reported in Uganda (40.1\%), Rwanda $(44.3 \%)$, and Mozambique (37.8\%) (WHO,2010) And also in India rates of meal frequency are low (41.5\%) (Patel et. al., 2012) .

\section{Minimum acceptable diet:-}

Minimum acceptable diet is a composite indicator that includes infants who have both adequate minimum meal diversity and minimum meal frequency .Only (40.8\%) of the study sample achieved the minimum acceptable diet criteria (Table 3); indicating that a greater proportion was either not given food from four or more of the recommended food groups in their diet or the meal frequencies were less than the recommended 2-4 times daily. This finding is similar to many studies. For example, the rate of minimum acceptable diet is (39.6\%) documented by Kabir (2012) in Bangladesh and the prevalence of minimum acceptable diet in infants aged 6-23 months is (44, 9\%) in Indonesia(Charmaine et. al., 2012). It is alarmingly low in India (9.2\%) (Patel et. al., 2012) . On the contrary, the rate of minimum acceptable diet in Sri Lanka is high (68\%) (Senarath et. al., 2012).

\section{Source of complementary feeding nutritional advice:-}

Television has an impact on improving introduction of solid foods. This could be related to improved awareness among mothers who have access to media (Patel et al,2012). In the present study, few mothers $(1.2 \%)$ obtained information from television (T.V). The majority of mothers $(71.3 \%)$ depended on the information that provided by other family member (Table 4). In the north of Iraq, (36.1\%) of mothers receive information about breast feeding and complementary feeding from their mothers or mothers in law (Shaker et al,2009). In Brazil, Caetano et al (2010) found that about $(67.6 \%)$ of mothers depended on their own and their family's life experience for the feeding practice. Likewise, in Ireland, maternal grandmother was the principal source of advice on infant feeding (Tarrant et. al., 2010).

\section{CONCLUSIONS}

Based on the findings of this study, it can be concluded that grain is the predominant type of food consumed by 6-23 months aged children followed by dairy products, fruits and vegetables, egg, vitamin A-rich fruits and vegetables, meat and finally legumes in decreasing frequency. The current prevalence of complementary feeding indicators including measured minimum dietary 
diversity and minimum acceptable diet attainment rate in Mosul city are not at satisfactory levels. Family was the principal source of advice on infant feeding practice.

\section{RECOMMENDATIONS}

The researchers recommended that mothers should be advised regarding appropriate child feeding practices to improve complementary feeding indicators outcome in Mosul city, possibly through exploiting mass media like television to ensure broad transmission of accurate and updated complementary feeding knowledge to the family as it is the main advice source to caregivers that led to undesirable feeding success rate.

\section{REFERENCES}

Batal, M., Boulghourjian, C., Akik, C. (2010). Complementary feeding patterns in a developing country: a cross-sectional study across Lebanon. Eastern Mediterranean Health Journal. EMHJ. 16(2). P.p.180-186.

Black, RE., Allen, LH., Bhutta, Z A., Caulfield, LE. (2008). Maternal and child undernutrition: Global and regional exposures and health consequences. Lancet. 371(9608). P.p. 243-60.

Caetano, MC., Ortiz, TT., da Silva, SG., de Souza, FI., Sarni, RO. (2010). Complementary feeding: inappropriate practices in infants. Brazil, J Pediatr. 86(3). P.p.196-201.

Caulfield, LE., DeOnis, M., Blössner, M., Black, RE. (2004). Undernutrition as an underlying cause of child deaths associated with diarrhea, pneumonia, malaria and measles. American Journal of Clinical Nutrition. 80. P.p193-198.

Charmaine, SN., Michael, JD., Kingsley, EA. (2012). Complementary feeding indicators and determinants of poor feeding practices in Indonesia. a secondary analysis of 2007 Demographic and Health Survey data, Public Health Nutrition. 15(5). P.p.827839.

Dang, S., Yan, H., Yamamoto, S., Wang, X., Zeng, L. (2005). Feeding practices among younger Tibetan children living at high altitudes. Eur J Clin Nutr. 59(9). P.p1022-29.

El-Zanaty, F., Ann Way. (2009). Egypt Demographic and Health Survey 2008. Cairo, Egypt. Ministry of Health, El-Zanaty and Associates, and Macro International .
Hope, LT., Gross, R., Giay, T., Sastroamidjojo, S., Schultink, W., Lang, NT. (2000). Premature Complementary Feeding Is associated with Poorer Growth of Vietnamese Children. $J$ Nutr. 130(11). P.p. 2683-90.

Hotz, C., Gibson, RS. (2001). Complementary feeding practices and dietary intakes from complementary foods amongst weanlings in rural Malawi. European J Clin Nutr. 55(10). P.p841-49.

Imdad, A., Yakoob, MY., Bhutta, ZA. (2011). Impact of maternal education about complementary feeding and provision of complementary foods on child growth in developing countries. BMC Public Health. P.p.3-25.

Joshi, N., Agho, KE., Dibley, MJ., Senarath, U., Tiwari, K. (2012). Determinants of complementary feeding practices in young children in Nepal: secondary data analysis of Demographic and Health Survey 2006. Maternal and Child Nutrition. 8(1). P.p. 4559.

Kabir, I., Khanam, M., Agho, KE., Mihrshahi, S., Dibley, MJ., Roy, SK. (2012). Determinants of inappropriate complementary feeding practices in infant and young children in Bangladesh: secondary data analysis of Demographic and Health Survey 2007. Maternal \& Child Nutrition. 8(1). P.p11-27.

Krebs, NF., Mazariegos, M., Tshefu, A., Bose, C., Sami, N., Chomba, E.,(2011) . Meat consumption is associated with less stunting among toddlers in four diverse low-income settings .Food \& Nutrition Bulletin ; 32(3):p185-191.

Kuriyan, R., Kurpad, AV.,(2012). Complementary feeding patterns in India. Nutrition, Metabolism \& Cardiovascular Diseases ;22(10):p799805.

Macharia-Mutie, CW., Brouwer, ID., Mwangi, AM., Kok, FJ. (2010). Complementary feeding practices and dietary intake among children 12-23 months in Mwingi district, Kenya. Journal of Food Safety. P.p 45-56.

Nasmah, NA., Mohammed, M. (2001). Malnutrition in children in Qadisyah. Iraqi J Commun. Med 2001. 14 (2). P.p.109- 11.

Nsour, F., Saleh, K., Aranki, I., Akeel, W., Alomari, Y., et al. (2008) . Jordan population and Family Health Survey 2007. Department of Statistics [Jordan] and Macro International Inc. 
PAHO and WHO. (2003). Guiding Principles for Complementary Feeding of the Breastfed child. Washington, D.C. Pan American Health Organization / World Health Organization .

Patel, A., Pusdekar, Y., Badhoniya, N., Borkar, J., Agho, KE., Dibley, MJ. (2012). Determinants of inappropriate complementary feeding practices in young children in India: secondary analysis of National Family Health Survey 2005-2006. Maternal \& Child Nutrition. 8(1). P.p.2844.

Paul, KH., Muti, M., Khalfan, SS., Humphrey, JH., Caffarella, R., Scoltzfus, RJ. (2011). Beyond food insecurity: how context can improve complementary feeding interventions. Food Nutr Bull. 32(3). P.p244-53.

Saleem, MB. (2006). Complementary foods for children under two years of age and its relation to nutritional status and selected socio-demographic factors in Basrah . Medical Journal of Basrah University. MJBU. 24(1\&2). P.p34-44 .

Senarath, U., Godakandage, SSP., Jayawickrama, H., Siriwardena, I., Dibley, MJ. (2012). Determinants of inappropriate complementary feeding practices in young children in Sri Lanka: secondary data analysis of Demographic and Health Survey 2006-2007. Maternal and Child Nutrition. 8(1). P.p. 60-77.

Shaker, NZ., Hussein, KA., AL-Azzawi, SI. (2009). Knowledge, Attitude and Practices (KAP) of Mothers toward Infant and Young Child Feeding in Primary Health Care (PHC) Centers, Erbil City. Hawler Medical University. P.p. 1-10.

Tarrant, RC., Younger, KM., Sheridan, PM., White, MJ., Kearney, JM. (2010).
Factors associated with weaning practices in term infants: a prospective observational study in Ireland. $\mathrm{Br} J$ Nutr. 104(10). P.p.1544-54.

WHO. (1998). Complementary feeding of young children in developing countries: a review of current scientific knowledge. Geneva, Switzerland: World Health Organization. Retrieved from www.whqlibdoc.who.int/hq/ 1998/WHO NUT 98.1.pdf on 12 Dec. 2012.

WHO.,(2000) .Nutrition throughout life. $4^{\text {th }}$ Report on The World Nutrition Situation. ACC/SCN(Administrative Committee on Coordination, sub-Committee on Nutrition). WHO. Geneva.

WHO. (2006). Complementary feeding in the WHO Multicentre Growth Reference Study. WHO Multicentre Growth Reference Study Group. Acta Pediatric. 450. P.p. 27-37.

WHO. (2008). Indicators for assessing infant and young child feeding practices. Part I: Definitions. Conclusion of a consensus meeting held 6-8 November 2007 in Washington, DC, USA. Geneva WHO. Retrieved fromhttp://www.who.int/nutrition/ publications/infantfeeding/9789241596664/e n/index.html on 25 Dec. 2012

WHO. (2010). Indicators for assessing infant and young child feeding practices. Part 3: Country Profile. Geneva WHO. Retrieved from http://whqlibdoc.who.int/publications /2010/9789241599290 eng. on 25 Dec. 2012.

World Bank. (2006). Repositioning Nutrition as Central to Development: A Strategy for Large Scale Action. The World Bank :Washington, DC. 